\title{
As divergências em análises fonológicas para o lkpeng (Karib)
}

\author{
Divergences in phonological analysis for Ikpeng (Karib)
}

Amanda Dias do Nascimento

Universidade Federal do Amapá ${ }^{1}$

Angela Fabiola Alves Chagas

Universide Federal do Pará2

Eduardo Alves Vasconcelos

Universiadade Federal do Amapá ${ }^{3}$

Resumo. Esse estudo tem por objetivo apontar as divergências encontradas nas análises fonológicas para a Língua Ikpeng (Família Karib, ramo pekodiano), que é falada por aproximadamente 500 pessoas que vivem em quatro aldeias no Parque Indígena do Xingu (PIX), Mato Grosso. A fonologia da língua Ikpeng foi discutida por Emmerich (1972), Campetela (1997) e Pachêco (2001). Entre essas análises, há diferenças tanto do número de fonemas como na distribuição de alofones. Em síntese, essas análises divergem quanto: ao status fonológico da consoante [b] e da distribuição dos alofones bilabiais entre $/ \mathrm{p} /$ e /w/; o status fonológico dos glides /w/ e /j/; a proposição de um fonema africado /t//; e, por fim, o status da oposição entre as velares $/ \mathrm{k} / \mathrm{e} / \mathrm{g} /$. Para realizar essa análise, foram utilizados os dados disponíveis nos textos desses pesquisadores, acrescentando exemplos extraídos de dez narrativas tradicionais gravadas por Chagas entre 2009-2015 e transcritas por professores e outros membros da comunidade Ikpeng.

Palavras-chave: Língua Ikpeng; Família Karib; Fonologia.

Abstract. This study aims to show the differences observed in the phonological analysis for the Ikpeng Language (Karíb Family, Pekodian branch), which is spoken by approximately 500 people who lives in four villages in the Parque Indígena do Xingu (PIX), Mato Grosso. The phonology of the Ikpeng language was discussed by Emmerich (1972), Campetela (1997) and Pachêco (2001). Among these analyzes, there are differences in the number of phonemes and in the distribution of allophones. In summary, these analyzes differ as to: the phonological status of consonant $[b]$ and the distribution of bilabial allophones between / $\mathrm{p} /$ and / $\mathrm{w} /$; the phonological status of the glides / $\mathrm{w} /$ and $/ \mathrm{j} /$; the proposition of a affricate phoneme / $\mathrm{t} /$; and, finally, the status of the opposition between the velars / $\mathrm{k} /$ and / $\mathrm{g} /$. To perform this analysis, the data available in the texts of these researchers were used, adding examples extracted from ten traditional narratives recorded by Chagas between 2009-2015 and transcribed by teachers and others members of the Ikpeng people.

Keywords: Ikpeng Language; Cariban family; Phonology.

\section{Introdução}

A presente análise tem por objetivo discutir a fonologia da língua Ikpeng (Família Karib, ramo pekodiano), tendo como ponto de partida as divergências encontradas entras as propostas de Emmerich (1972), Campetela (1997) e Pachêco (2001), as quais elencamos a seguir:

\footnotetext{
${ }^{1}$ Graduada em Letras Português/Inglês pela Universidade Federal do Amapá (UNIFAP).

${ }^{2}$ Professora do Programa de Pós-Graduação em Letras da Universidade Federal do Pará (PPGL/UFPA).

${ }^{3}$ Professor do Programa de Pós-Graduação em Letras da Universidade Federal do Amapá (PPGLET/UNIFAP).
} 
i. Status da consoante [b], considerada um fonema na análise de Emmerich (1972) e um alofone de /w/ e de /p/ em Campetela (1997) e Pachêco (2001);

ii. Acresce-se à divergência de (i) a distribuição das consoantes fricativas labiais [ $\beta]$ e $[\phi]$. Essa última corresponde a $\left[\mathrm{p}^{\mathrm{h}}\right]$ por Emmerich (1972), realizada somente da vogal posterior [u].

iii. Proposição, por Pachêco (2001) e Campetela (1997), de um fonema / $\mathrm{t} /$, que Emmerich (1972) analisa como a realização de /t/ diante da vogal /i/;

iv. Status fonológico e processos morfofonológicos relacionados às consoantes obstruintes velares /g/ e /k/;

v. Status fonológico / $\mathrm{w} /$ e /j/ e suas relações com as vogais assilábicas [i] e [u] , interpretados como vogais assilábicas por Emmerich (1972), como semivogais (ou semiconsoantes) em Campetela (1997) e, em Pachêco (2001), é inserida a diferenciação entre glides consonantais /y/ e /w/, portanto, fonemas, e glides derivados, [i] e [u], alofones dos fonemas /i/ e /u/, respectivamente.

Os dados utilizados nessa investigação são oriundos de dissertações de mestrado Emmerich (1972); Pachêco (1997); Campetela (1997) - e teses de doutorado - Pachêco (2001); Campetela (2002); Chagas (2013). Utilizaremos também dez narrativas gravadas por Chagas entre 2009-2015, transcritas por professores e outros representantes dos Ikpeng.

O povo Ikpeng se distribui em quatro aldeias - Arawo, Rayo, Tupara e Moygu - no Parque Indígena do Xingu (PIX), onde vive desde 1967. Segundo dados do Siasi/Sesai (disponível no site do ISA $)^{4}$, em 2014, a população Ikpeng contava com 477 indivíduos.

\section{Propostas fonológicas apresentadas à Língua Ikpeng}

Nessa seção, discutiremos as divergências entre as análises, buscando identificar os seus status fonológicos. Para cada caso, apresentaremos uma síntese das propostas das três análises, como forma de comparar as semelhanças e as diferenças presentes nessas propostas. Em seguida, apresentaremos os exemplos extraídos das narrativas coletadas e tratadas por Chagas, que possam corroborar uma das interpretações ou hipóteses alternativas.

Segmento $[\mathrm{b}]$

A investigação de Emmerich (1972) é a única que aponta /b/ como fonema, com os alofones $\left[b_{n}\right]^{5}$ e $[\beta]$, os quais variam livremente em contexto intervocálico.

(01) [o'bet'] [o'ßet']

(02) [aba'nãn] [aßa'nãn]

(03) [ara'but'] [ara'ßut'] 'tua coxa' (EMMERICH, 1972, p. 8)

'tua orelha' (EMMERICH, 1972, p. 8)

'ele briga' (EMMERICH, 1972, p. 8)

\footnotetext{
${ }^{4}$ https://pib.socioambiental.org/pt/povo/ikpeng/608

${ }^{5}$ Segundo a autora [b] "oclusiva bilabial, sonora, lenis, explodida" (Emmerich, 1972, p. 8)
} 
As relações opositivas entre os segmentos /p/ e /b/ foram reafirmadas através dos seguintes pares mínimos e análogos:

$/ \mathrm{p} /-/ \mathrm{b} /$

(04.a) /uapon/ [una'põn] 'tua borduna' (EMMERICH, 1972, p. 24)

(04.b) /uabon/ [una'ßõn] 'tua pena' (EMMERICH, 1972, p. 24)

(05.a) /parapi/ [para'pi] 'borboleta' (EMMERICH, 1972, p. 25)

(05.b) /arabi/ [ara'ßi] 'feijão' (EMMERICH, 1972, p. 25)

Um dos elementos importantes nessa análise é a oposição dos traços tenso vs. lenis que distingue os fonemas oclusivos desvozeados, marcado como tenso, dos vozeados, marcado como lenis ${ }^{6}$. Assim, Emmerich (1972) propõe um fone oclusivo bilabial vozeado com tensão [b] com ocorrência registrada somente diante de líquidas e, por este fato, atribuído ao fonema /p/ sob a justificativa de que sua sonoridade é resultado da assimilação do ambiente fonológico.

(06) [I'b $\underline{b} r i]$

(07) [I'blit] 'flecha dele' (EMMERICH, 1972, p. 8)

'eu me banhei' (EMMERICH, 1972, p. 8)

A reanálise de Campetela (1997) não interpreta [b] como fonema, além de não considerar relevante a oposição tenso vs. lenis empregada por Emmerich (1972), buscando "demonstrar a irrelevância da subdivisão de /p/ em /p/ e /b/" (CAMPETELA, 1997, p. 30). Na sua distribuição de alofones, a pesquisadora identifica somente o fone $[b]$, que se realiza diante de líquidas, conforme observamos no exemplo (08.a). Por conta do seu padrão distribucional, [b] foi incorporado ao conjunto de alofones de $/ p /$, como uma realização desse fonema quando precedendo consoantes líquidas, exemplos (08.b) e (08.c). Quanto à fricativa bilabial sonora [ $\beta]$, em Emmerich (1972), alofone de /b/, é interpretada por Campetela (1997) como alofone do glide /w/.
(08.a) [obro]
'suas nádegas' (CAMPETELA, 1997, p. 31)
(08.b) [marep]
'você chega' (CAMPETELA, 1997, p. 31)
(08.c) [marebli]
'você chegou' (CAMPETELA, 1997, p. 31)

A proposta de Pachêco (2001, p. 37) segue Campetela (1997) quanto à interpretação do fone [b], visto que a oclusiva bilabial sonora é compreendida como alofone de $/ p /$ diante de consoantes líquidas, como é possível constatar no exemplo (09). Já a fricativa bilabial sonora [ $\beta$ ] figura tanto entre os alofones de /p/ como de /w/, nos dois casos em contextos intervocálicos. Mais adiante faremos uma discussão específica sobre a fricativa [ $\beta]$.

(09) /karepliz [kareb'li $]$ 'eu cheguei' (PACHÊCO, 2001, p. 37)

\footnotetext{
${ }^{6} \mathrm{O}$ traço tense/lax é proposto por Jakobson, Fant \& Halle (1952). As consoantes lenis são aquelas marcada como [lax], enquanto as consoantes fortis são marcadas por [tense]. Câmara Jr. (1972), traduz esse traço como tenso/frouxo.
} 
Para este segmento foram apresentadas duas propostas, a de Emmerich (1972), em que /b/ é um fonema, e Campetela (1997), corroborada por Pachêco (2001), em que [b] é um alofone de /p/ diante de líquidas. Para essa discussão, apresentamos os exemplos encontrados nas narrativas interlinearizadas ${ }^{7}$ por Chagas:

\begin{tabular}{|c|c|c|}
\hline (10) - & $\begin{array}{l}\text { ïprï } \\
\text { [i'bri] }\end{array}$ & $\begin{array}{l}i m e !^{8} \\
{\left[1^{\prime} m \varepsilon\right]}\end{array}$ \\
\hline & $\begin{array}{l}\text { Ï-ip-rï } \\
\text { 1P-flecha-gen. mãe } \\
\text { 'quero minha flecha, } n\end{array}$ & $\begin{array}{l}\text { ime } \\
\text { Iãe!' }\end{array}$ \\
\hline
\end{tabular}

(11) - werangoplï

[we.rã.no'bli]

werangopli !

(WAYMAN MÏRAN - HISTÓRIA DO JABUTI)

wï-rangop-lï

[we.rã.no'blì]

wï-rangop-lï

2A>1P-assustar-PAS.IM

2A>1P-assustar-PAS.IM

'você me assustou, você me assustou!'

(12) - yïnkilï

[yi.ki'li]

otkanoplan

(OKOLOY MÏRAN - HISTÓRIA DO MEL)

y-ïnkï-lï

[at'.kã.no'blãn]

3P-dormir-PAS.IM INTR-pensar-PAS.IM

'(ele) pensou que ela tinha dormido'

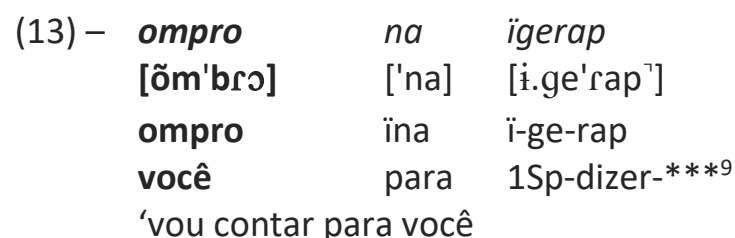

(RERE MIIRAN - HISTÓRIA DO MORCEGO)

(COMO SE FAZ BORDUNA)

Nesses exemplos (10-13), temos a ocorrência do fone [b] em posição de ataque ramificado com consoantes líquidas, / $/$ / e /l/, formando sílabas do tipo [CCV]. Nesses exemplos, podemos observar que o fone [b] ocorre em fronteira de morfema, quando um morfema terminado em /p/ se concatena a morfemas iniciados em consoantes líquidas / $\mathrm{r} / \mathrm{e} / \mathrm{I} /$, as quais possuem o traço [+vozeado]. Em (11), por exemplo, quando o radical terminado em /p/ recebe o morfema indicador de passado imediato, $\{-\mid \boldsymbol{t}\}$, o fonema [- vozeado] assimila o traço de vozeamento da consoante líquida /// e então passa a se realizar como o segmento oclusivo bilabial vozeado [b].

Todavia, encontramos uma ocorrência em que a assimilação do traço [+ vozeado] não ocorre em fronteira de morfema e sim dentro da palavra, se trata do pronome de segunda pessoa ompro expresso em (13). Uma análise possível seria considerar esse contexto como fronteira de morfema, uma vez que -ro também ocorre com uro, 'pronome de primeira pessoa, e uguro, 'primeira pessoa

\footnotetext{
${ }^{7}$ Interlinearização é a glosagem das unidades lexical e morfológica.

${ }^{8}$ Nos exemplos retirados de narrativas: i) a primeira linha corresponde à transcrição da narrativa; ii) a segunda linha à transcrição fonética; iii) a terceira linha contém os morfemas; iv) a quarta linha a glosa lexical; v) a quinta linha apresenta a tradução livre do trecho retirado.

${ }^{9} \mathrm{O}$ uso dos asteriscos marca palavras ainda não traduzidas pelos Ikpeng responsáveis pela transcrição da narrativa.
} 
inclusiva'10. Se confirmada a hipótese de fronteira de morfema em (13), a assimilação de vozeamento pelo fonema /p/ seguiria o padrão encontrado nos exemplos (10), (11) e (12). As ocorrências como a de (13) necessitam de mais investigação.

Finalizando, interpretamos o segmento [b] como resultado de um processo de vozeamento sofrido pelo fonema /p/ diante de consoantes líquidas, que provavelmente ocorre em fronteira de morfema. Esse processo pode ser observado com as demais oclusivas desvozeadas diante de consoantes líquidas, tal como em lak 'saliva' e olaglu 'tua saliva' (as oclusivas velares serão discutidas mais adiante).

\section{Segmento [t $]$}

Emmerich (1972, p. 11) aponta [t $\mathrm{f}$ ] como uma consoante "africada alveolar surda palatalizada; ocorre em posição inicial, depois de oclusiva surda e de nasal não-homorgânica; em posição intervocálica alterna livremente com [ś], exceto diante /i/, ambiente em que só ocorre [tś]"11. Ao discutir o fonema /t/, a autora faz notar que não há registros de ocorrência dessa consoante precedendo a vogal alta /i/, ambiente em que só é possível encontrar a africada, o que indicaria que [t $\int$ ] como alofone de /t/ em uma distribuição complementar. Emmerich (1972) propõe duas soluções:

(a) Atribuir a africada ao fonema /t/. Desta forma seria preenchida a lacuna distribucional diante /i/. Porém, como interpretar então oposições do tipo [teřu'ka] 'você quer?' e [tśeřu'ka] 'coati'; [tã'nok=] 'vivo' e [tśano'le‘] 'agora', uma vez que [tś], em posição inicial e em posição intervocálica, onde alterna livremente com [ś], também ocorre diante das demais vogais? (EMMERICH, 1972, p. 26).

(b) [...] mais viável parecia a hipótese de interpretá-lo como fonema /č/ ${ }^{12}$, foneticamente complexo. Esta interpretação, no entanto, acresceria o inventário de um fonema, atingindo o seu princípio de economia e simetria, já que /č/ passaria a ocupar uma posição isolada no sistema. Ademais, o fonema / $t$ / apresentaria uma lacuna distribucional decorrente da neutralização de /t/ e /č/ diante vogal alta não-arredondada (EMMERICH, 1972, p. 26).

A opção da pesquisadora é a favor da opção em (a), explicando que os fones [t $\left.\int\right]$ e [ $]$ ] "como uma sequência fonêmica de /t/ mais /i/" (EMMERICH, 1972, p. 26). Sua escolha tem por base a estrutura silábica da língua Ikpeng, que, segundo a pesquisadora, tem /CV/ como um padrão silábico funcional e frequente. Logo [t $\int$ ] foi incorporado ao conjunto de alofones de /t/ com ocorrência condicionada pela vogal /i/.

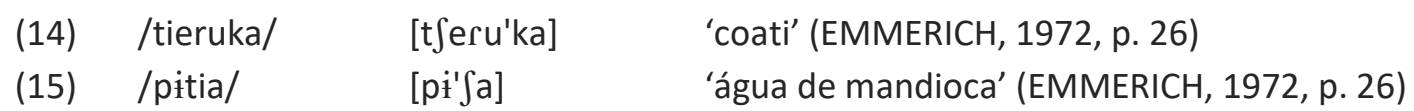

\footnotetext{
${ }^{10}$ A série de pronomes pessoais proposta por Pachêco (2001, p. 119) e adotada por Chagas (2013) apresenta os lexemas uro e omro para primeira e segunda pessoa do singular, respectivamente; ugro e tximna para o singular de primeira pessoa inclusiva e exclusiva, nesta ordem; e omronmo e ugroymo para o plural de segunda pessoa e primeira pessoa inclusiva.

${ }^{11}$ Optamos por manter os símbolos utilizados pela autora.

12 A autora parece fazer uma distinção entre [tś] e [č], em que o primeiro seria uma "africada, alveolar, surda, palatalizada" (EMMERICH, 1972, p. 11) e o segundo [č], "foneticamente complexo".
} 
O posicionamento de Campetela (1997) para a africada / $\mathrm{t} \int /$ se baseia na proposta de Seki e Gildea, explicando que:

Seki e Gildea, em 1994, reconsiderando o quadro fonológico proposto por Emmerich, porém sem elaborar uma análise propriamente dita, concluíram que $\left[\mathrm{t} \int\right]$ é um fonema distinto de [t], porque contrastam nos mesmos ambientes de realização, com uma exceção: não ocorre /t/ precedendo /i/, por condicionamento fonético. (CAMPETELA, 1997, p. 35)

Como forma de demonstrar a autonomia de /t $\mathrm{f} /$ e sua oposição a /t/, a pesquisadora nos oferece os seguintes exemplos:

(16.a) [t $\mathrm{tu}]$

(16.b) [tukto]

(17.a) [t Simna]

(17.b) ----

(18.a) [t Seluka]

(18.b) [tereykeni]

(19.a) [itfap]

(19.b) [tae] 'estou deitado' (CAMPETELA, 1997, p. 36)

'roça' (CAMPETELA, 1997, p. 36)

'nós (PRO)' (CAMPETELA, 1997, p. 36)

'quati' (CAMPETELA, 1997, p. 36)

'garrafa' (CAMPETELA, 1997, p. 36)

'posso banhar?' (CAMPETELA, 1997, p. 36)

'macaco' (CAMPETELA, 1997, p. 36)

Pachêco (2001) concorda com a análise desenvolvida por Campetela (1997), em que interpreta / $\mathrm{t} /$ como fonema, ao mesmo tempo em que atribui a africada ao conjunto alofônico de /t/, com ocorrência condicionada ao aparecimento de vogal alta não-posterior /i/. Nessas duas reanálises, a variação da africada [t] com a fricativa [S], citada por Emmerich (1972), não é retomada. Os exemplos seguintes demonstram a autonomia de $/ \mathrm{t} \mathrm{s} /$ :

(20) /t Soum/

(21) /pitsa/ ['t $\int$ ouñ $]$ ['țounmo ] 'peixe corvina' (PACHÊCO, 2001, p. 38)

[pi't $\mathrm{pa}$ [pi't ța] 'mingau perereba' (PACHÊCO, 2001, p. 38)

Existem duas propostas de interpretação para o segmento [t $\left.\int\right]$, na primeira, formulada por Emmerich (1972), uma sequência fonêmica de /t/ mais /i/, logo, [t $\int$ ] funcionaria somente como alofone de /t/ diante de vogal alta não-posterior /i/. Outra proposta, Campetela (1997), posteriormente reafirmada por Pachêco (2001), admite a africada / $\mathrm{t} /$ / como fonema por sua ampla ocorrência perante as vogais da língua, apesar de manter, no conjunto alofônico de /t/, a realização dessa africada (caso de overlapping). De posse dessas informações, apontaremos abaixo ocorrências do fone [t $\mathrm{t}$ ] para em seguida discutirmos o status fonológico do segmento em questão:

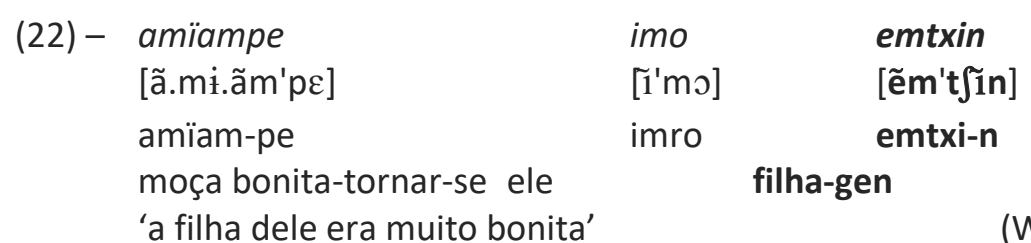

(WAYMAN MÏRAN - HISTÓRIA DO JABUTI) 


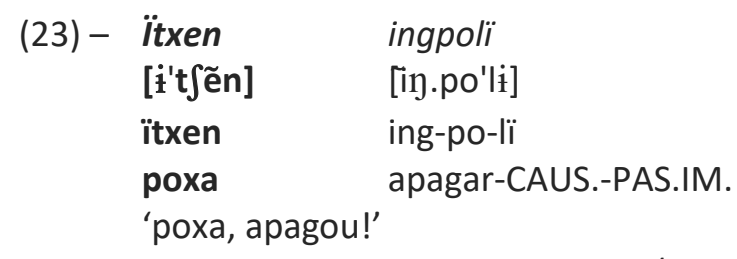

\begin{tabular}{|c|c|c|}
\hline (24) - & $\begin{array}{l}\text { kïrïp } \\
\text { [ki'rip’] }\end{array}$ & $\begin{array}{l}\text { metxan } \\
\left.\text { [me't } \int a ̃ n\right]\end{array}$ \\
\hline & $\begin{array}{l}\text { kïrïp } \\
\text { preto, escuro }\end{array}$ & $\begin{array}{l}\text { m-e-txi } \\
\text { 2A-ficar-N.PAS }\end{array}$ \\
\hline
\end{tabular}

'está bem você vai se pintar só de preto'

$\begin{array}{lllll}\text { txurun } & \text { pomri } & \text { umi } & \text { emkule umi } & \\ \left.\text { [t } \int u^{\prime} r u ̃ n\right] & \text { [põm'ri] } & \text { [ũ'mi] } & \text { [ẽm.ku'le] } & \text { [ũ'mi] } \\ \text { txurun } & \text { pomri } & \text { umi } & \text { emkule } & \text { umi } \\ \text { pássaroadolescente } & \text { alimento } & * * * * * * & \text { alimento } & \\ \text { 'o adolescente pode comer o pássaro txurun' } & & \end{array}$

(26)

\section{Txotïk \\ [t $\int o^{\prime}$ tik'] $^{\top}$ \\ txotïk}

fase em que a criança começa a sentar sozinha

(WATPÏRO MIIRAN - LIVRO SOBRE NUTRIÇÃO)

(WATPÏRO MÏRAN - LIVRO SOBRE NUTRIÇÃO)

Nos exemplos de (22-26), podemos observar que a africada ocupa apenas a posição de ataque na sílaba e forma sílabas /CV/ podendo estar em ataque inicial (25) ou medial (23). Observese ainda que esse segmento ocorre amplamente diante das vogais Ikpeng, exceto a vogal alta posterior não-arredondada /ì/, ambiente em que só ocorre a oclusiva alveolar $/ \mathrm{t} /{ }^{13}$. Apesar de não termos encontrado um par mínimo diferente do apresentado por Emmerich (1972), acreditamos que a africada é mais bem compreendida como um fonema, porque além da ampla ocorrência deste fone, podemos encontrar alguns pares análogos entre / $t$ / e / $\mathrm{t} f$ / que reforçam a oposição entre estes segmentos:
(27.a) [t Selu'pi]
'pintado' (PACHÊCO, 2001, p. 226)
(27.b) [telapu'rẽm] 'barbudo' (PACHÊCO, 1997, p. 46)
(28.a) [t $\left.\int a ̃ n o ' l \varepsilon\right]$
'agora, hoje' (EMMERICH, 1972, p. 26)
(28.b) [tã'nok']
'vivo' (EMMERICH, 1972, p. 26)

Existem duas possibilidades de interpretação que nos ajudam a explicar a aparente lacuna distribucional dos fonemas /t/ e /t $\int$ / diante de vogais altas não-arredondadas /i/ e /i/, quais sejam: (a) por distribuição complementar; e (b) neutralização.

Na hipótese (a), distribuição complementar, os fonemas /t/ e /t $\int /$ possuem os alofones [t $\left.\int\right]$ e [t], respectivamente, em que o alofone [t $]$ ocorre diante de vogal [+ alta] [+ posterior] /i/ e [t]

\footnotetext{
${ }^{13}$ Essa lacuna distribucional não foi observada nas análises fonológicas da língua Ikpeng. Além disso, segundo Alves (2013), o Arara, língua pertencente ao ramo pekodiano da família Karib, apresenta essa mesma lacuna.
} 
ocorre diante de vogal [+ alta] [- posterior] /it/. Nesse caso, em overlapping, /t/ teria um alofone [t]] $\mathrm{e} / \mathrm{t} f /$ um alofone [t].

Na hipótese (b), neutralização, a oposição entre /t/ e /t $\int /$, atestada com as demais vogais, é neutralizada nas vogais altas não-arredondadas /i/ e /ił/. Assumindo-se essa hipótese, é preciso, para uma melhor descrição do fenômeno, observarmos se estamos tratando de duas neutralizações - uma envolvendo a vogal /i/ e outro envolvendo a vogal / $\mathrm{t}$ / - ou uma neutralização que envolve o $\operatorname{par} / \mathrm{t} / \mathrm{e} / \mathrm{t}$ / e os traços [+alto] e [-arredondado], com resultados diferentes para /i/, ocorrência de $/ \mathrm{t} \int /$, e / $\mathrm{t} /$, ocorrência de $/ \mathrm{t} /$.

Considerando que as oposições na língua não ocorrem de forma aleatória, assumimos que /t/ e /t / são fonemas, ou seja, são um par opositivo, neutralizável diante vogais [+alto, -arr.], com resultados fonéticos diferentes: [t] se vogal [+posterior] e [t]] se vogal [-posterior].

Segmentos $[\beta]$ e $[\phi]$

A proposta de Emmerich (1972) conta com a oposição /p/ x /b/ no quadro de fonemas, em que $/ \mathrm{p} /$ tem, entre seus alofones, a oclusiva bilabial surda fortis aspirada $\left[\mathrm{p}^{\mathrm{h}}\right]$ e /b/ possui a fricativa bilabial sonora [ $\beta]$. Segundo a autora, a aspirada ocorre apenas diante de vogal alta posterior /u/, ambiente em que não se registrou ocorrências do fonema /p/, por esse motivo o segmento oclusivo aspirado $\left[\mathrm{p}^{\mathrm{h}}\right]$ foi compreendido como alofone de $/ \mathrm{p} /$ diante de vogal $/ \mathrm{u} /{ }^{14}$ :
(29) $\quad\left[p^{\mathrm{h}} u^{\prime} p a\right]$
'papai (vocat.)' (EMMERICH, 1972, p. 6)
(30) [i'p $p^{\text {h }}$ nn
'meu pé' (EMMERICH, 1972, p. 6)
(31) $\quad\left[\varepsilon\right.$ ret $\left.{ }^{\prime \prime} p^{\mathrm{h}} u t^{\prime}\right]$
'cabelo dele' (EMMERICH, 1972, p. 6)

A fricativa [ $\beta$ ] foi interpretada como alofone do fonema /b/, alternando, em variação livre, com o alofone [b] em ambiente intervocálico.
(32) [o'bet $] \sim\left[\mathrm{o}^{\prime} \beta \mathrm{Bet}{ }^{\top}\right]$
'tua coxa' (EMMERICH, 1972, p. 8)
(33) [aba'nãn] [aßa'nãn]
'tua orelha' (EMMERICH, 1972, p. 8)
(34) [ara'but'] [ara' $\beta$ ut? $]$
'ele briga' (EMMERICH, 1972, p. 8)

A reanálise de Campetela (1997), coloca a fricativa [ $\beta]$ no conjunto alofônico do glide /w/, explicando que a fricativa vozeada e o glide [w] compartilham os traços [- vocálico] e [-consonantal] (CAMPETELA, 1997, p. 30) ${ }^{15}$. Focando sua análise na distribuição dos fones [ß] e [w], a pesquisadora observa que a fricativa vozeada ocorre diante de vogal alta não-posterior /i/ e diante do tepe /r/, enquanto, diante das vogais /a/, /e/ e /o/, realiza-se o glide [w] (CAMPETELA, 1997, p. 32). Reproduzimos a seguir distribuição observada pela pesquisadora:

\footnotetext{
${ }^{14}$ Emmerich (1972) ainda identifica as seguintes consoantes aspiradas: [ $\left.\mathrm{t}^{\mathrm{h}}\right]$ diante $[\mathrm{u}] ;\left[\mathrm{k}^{\mathrm{h}}\right]$ diante $[\mathrm{i}]$.

15 Pelo seu caráter obstruinte, a fricativa [ $\beta$ ] é [+consonantal], contudo, é importante ressaltar que Campetela (1997) utiliza o símbolo [b], que em Emmerich (1972) é descrito como "fricativa plana, bilabial, sonora” (p. 11). 
(35) Distribuição de [ß] e [w] segundo Campetela (1997, p. 32)

$\begin{array}{ll}\text { aßiana } & {[\beta]} \\ \beta \text { ilo } & {[\beta]} \\ \phi u \beta i & {[\beta]} \\ \text { o } \beta r o & {[\beta]} \\ \text { taßru } & {[\beta]} \\ \text { warap } & {[w]} \\ \text { werem } & {[w]}\end{array}$

Quanto à reanálise dos segmentos labiais, Campetela (1997, p. 31) também apresenta a distribuição do segmento [ $[\uparrow]$, o qual interpretamos como a fricativa $[\phi]$, uma vez que a pesquisadora atribui a [ $\uparrow$ ] os seguintes traços [-const. Labial], [-vozeado] e [+contínuo], os mesmos a serem atribuídos a fricativa $[\phi]$.

É importante ressaltar que a fricativa [ $\phi]$ em Campetela (1997) tem a mesma distribuição da aspirada $\left[\mathrm{p}^{\mathrm{h}}\right]$ em Emmerich (1972), a saber: ataque silábico, precedendo a vogal posterior alta [u], o que nos leva a assumir que a aspirada $\left[\mathrm{p}^{\mathrm{h}}\right]$ corresponde a fricativa $[\phi]$, apesar da ausência de uma discussão que aponta o motivo da correspondência. Os exemplos seguintes reproduzem aqueles de Campetela (1997, p. 31).

$\begin{array}{lll}(36) & {[i ' \phi u n]} & \text { 'pé' } \\ (37) & {[\text { inu' } \phi u]} & \text { 'pupila' } \\ (38) & {\left[\text { tak } \phi u^{\prime} r u\right]} & \text { (nome próprio) }\end{array}$

Seguindo Campetela (1997), Pachêco (2001) compreende a fricativa bilabial sonora [ $\beta$ ] como alofone do glide /w/, porém sua proposta se diferencia quando afirma que "os glides /w/ e /y/ se realizam geralmente como fricativas sonoras" (PACHÊCO, 2001, p. 36), pois, em Campetela (1997), a fricativa sonora apresenta ocorrências somente diante do tepe /r/ e da vogal/i/, enquanto o glide /w/ aparece diante das demais vogais. Abaixo temos as ocorrências da fricativa [ $\beta$ ] em Pachêco (2001):

\begin{tabular}{|c|c|c|c|}
\hline (39) & /awiana/ & [aßૂia'na] & 'porco queixada' (PACHÊCO, 2001, p. 36) \\
\hline (40) & /tawule/ & [taßu'le] & ‘leve’ (PACHÊCO, 2001, p. 36) \\
\hline (41) & /t $\int i w a n /$ & [t $\left.\int i^{\prime} \beta a n\right]$ & ‘arraia' (PACHÊCO, 2001, p. 36) \\
\hline
\end{tabular}

Além da divergência quanto a distribuição do alofone [ $\beta]$ no conjunto alofônico de [w], Campetela (1997) e Pachêco (2001) divergem quanto à interpretação de [ $\beta]$ como um alofone de /p/. Para Pachêco (2001), a fricativa vozeada está em distribuição complementa com [p], em que $[\beta]$ é realização fonética em ambiente intervocálico, como ilustrado no exemplo seguinte.

Quanto à fricativa bilabial desvozeada $[\phi]$, Pachêco (2001) concorda com a proposta de Campetela (1997) de que este segmento é alofone de /p/ diante vogal /u/.

(43) /ipun/ [i'фun] 'pé dele' (PACHÊCO, 2001, p. 37) 
Por fim, teríamos em Pachêco a seguinte distribuição para os segmentos labiais ${ }^{16}$ :

Quadro 1: Distribuição dos segmentos labiais em Pachêco (2001)

\begin{tabular}{|c|c|c|c|}
\hline Fonema & Alofone & Contexto & Exemplo \\
\hline$/ \mathrm{p} /$ & {$[\phi]$} & Diante vogal posterior arredondada [u]. & /ipun/ [i'фun] 'pé dele' \\
\hline & {$[\mathrm{b}]$} & Diante líquidas. & /kareplì [kareb'li] 'eu cheguei' \\
\hline & {$[\beta]$} & Entre vogais. & /ipari/ [ißßa'ri] 'meu amigo' \\
\hline & {$[\mathrm{m}]$} & Antes de consoante nasal. & /irip nole/ [kirimno'le] 'de manhã' \\
\hline & {$[\mathrm{p}]$} & Nos demais contextos. & /petkom/ [pet'kom] 'mulher' \\
\hline$/ \mathrm{w} /$ & {$[\beta]$} & Não especificado em Pachêco (2001). & /tawule/ [taßu'le] 'leve' \\
\hline
\end{tabular}

Começaremos com a revisão da fricativa bilabial vozeada [ [ ] apontada por Emmerich (1972) como alofone de /b/ com ocorrência atestada apenas em ambiente intervocálico. Este segmento foi compreendido por Campetela (1997, p. 30) como alofone do glide /w/ por dois fatores, além de atestar a inexistência do fonema /b/, a fricativa [ $\beta$ ] se assemelharia a /w/ pelo traço [-consonantal] e [-vocálico], porém, é importante destacar que, foneticamente, essa consoantes teria o traço [+consonantal], se diferenciando das oclusivas pelo traço [ \pm contínuo], no caso, [ $\beta]$ [+ contínuo], esse sim um traço compartilhado com [w].

Pachêco (2001) concorda com a última proposta que classifica [ $\beta]$ como alofone do glide /w/, no entanto, a fricativa bilabial vozeada também foi atribuída ao fonema /p/ quando esse encontrase entre vogais. Separamos alguns dados provenientes de narrativas para em seguida discutirmos o status do presente fone:

\begin{tabular}{|c|c|c|c|c|}
\hline $\begin{array}{l}\text { Ketpotke } \\
{\left[k^{\prime} \mathrm{t}^{\urcorner} \cdot \text { pot }^{\prime} \mathrm{k} \varepsilon \varepsilon\right]}\end{array}$ & $\begin{array}{l}\text { rwam } \\
\text { [ru'ãm] [r }\end{array}$ & $\begin{array}{l}\text { marawyapton } \\
\text { wi.ap"tõn] }\end{array}$ & ['mãn] & [tõy'pe] \\
\hline $\begin{array}{l}\text { ketpotke } \\
\text { por isso**** }\end{array}$ & $* * * *$ & $\begin{array}{l}* * * * * * * * * * * \\
* * * * *\end{array}$ & assim & tongpe \\
\hline $\begin{array}{l}\text { txiga } \\
\text { [t]i'ga] }\end{array}$ & $\begin{array}{l}\text { wok } \\
\text { ['wok'] }\end{array}$ & $\begin{array}{l}\text { tïmoyp } \\
\text { [ti.mo'ip’] }\end{array}$ & 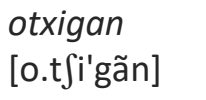 & $\begin{array}{l}\text { pok } \\
\text { ['pok'] }\end{array}$ \\
\hline$* * * * *$ & pok & $* * * * * * * * * * * *$ & pok & \\
\hline$k * * *$ & em, sobre & $* * * * * * * * * * *$ & em, sobre & \\
\hline
\end{tabular}

'Exemplo disso filho, quando vai para uma guerra sempre é bom fazer o beiju no pátio da casa'

(45.a) Putxagat, putxagat, kenang maneptxinorong

(WAYMAN MÏRAN - HISTÓRIA DO JABUTI)

[фu.t [a'gat $\left.^{\urcorner}\right]$

[фu.t $\left.\int a ' g a t{ }^{\urcorner}\right]$

[ke'nãy]

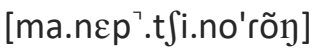

ke-nang

$\mathrm{m}$-anep-txi-norong

$* * * * * * * *$

fazer-PROG. 2A-trazer-N.PAS.

paraktxi

'Ao pisar no chão o pé dele entrava na terra'

(45.b) Owro

waraktxi

omomli

[o.mõm'lì]

[ow'ro]

[wa.rak"t $t \mathrm{i}$ ]

ø-omom-lï

casa

paraktxi

para dentro de 3Sa-entrar-PAS.IM. NEG.

'Ele não entrou na casa'

[pa.rak"t $t \mathrm{fi}]$
paraktxi
para dentro de

(HISTÓRIA DO ALAKANA) ïgemnï.

[i.gẽm'ni]

ïgemnï

(HISTÓRIA DO ALAKANA)

\footnotetext{
${ }^{16}$ Adaptado do quadro apresentado em Pachêco (2001, p. 37). Seguimos os símbolos adotados pelo autor para os exemplos.
} 
Através dos exemplos acima podemos observar que o fonema /p/ se realiza foneticamente como o glide $[w]$ quando está entre vogais em fronteira de palavra, essa variação não foi encontrada em outros ambientes fonológicos, ou seja, o processo estaria restrito à fronteira de palavras. Atentamos para o fato de que dispomos de poucos dados e um futuro trabalho de campo, em que se possa fazer testes quanto à fronteira de palavras e de morfemas permita verificar a hipótese proposta por Pachêco (2001), esclarecendo, assim, a ocorrência da fricativa bilabial vozeada [ $\beta]$ na língua Ikpeng. Por fim destacamos que Meira e Francheto (2005) consideram que uma das mudanças diacrônicas do Ikpeng foi o surgimento do glide [w] como alofone de /p/ entre vogais.

Sobre o alofone de /p/ que ocorre diante de vogal alta arredondada / $\mathrm{u} /$ temos duas interpretações divergentes. Na primeira, apresentada por Emmerich (1972), foi descrita a oclusiva aspirada $\left[\mathrm{p}^{\mathrm{h}}\right]$, ao passo que na segunda, Campetela (1997), identifica-se a ocorrência da fricativa bilabial desvozeada [ $\phi$ ]. Essa última é corroborada por Pachêco (2001). A análise dos segmentos [ $\mathrm{p}^{\mathrm{h}}$ ] e $[\phi]$ se dará após os exemplos abaixo:

$\begin{array}{cll}\text { (46) - Eng } & \text { oren } & \text { pupa } \\ \text { ['ẽ̃] } & \text { [o'rẽn] } & {\left[\phi u^{\prime} p a\right]} \\ \text { eng } & \text { oren } & \text { pupa } \\ \text { olho } & \text { esse (visível) } & \text { papai (voc.) }\end{array}$

'é um fulano de tal, papai'

[фurõn'pe] [tẽnpa'nop'] [tĩnkit'kerẽmto'wop?]

puron-pe tenpano-pe $* * * * * * * * * * * * * * *$

sapo-tornar-se pessoa-tornar-se vivia

'Fique como o sapo. Antes você vivia como gente'

(48) pïrïgop nole metputket

(PURON MÏRAN - HISTÓRIA DO SAPO)

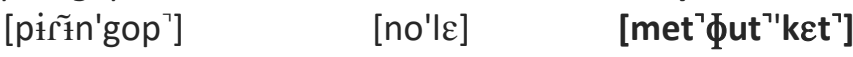

pïrïngop nole m-etpo-tke-txi

primeiro ainda 2A-cortar-ITER.-N.PAS.

'primeiro você tem que rachar'

(49)

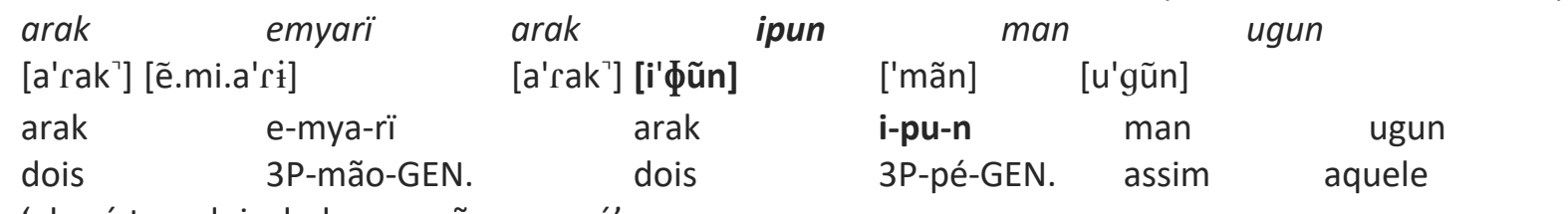

(WAGO MÏRAN - HISTÓRIA DO MACACO PREGUIÇA)

Os dados apontam que sempre que o fonema $/ \mathrm{p} /$ se encontra diante de $/ \mathrm{u} /$, esse se realiza foneticamente como a fricativa bilabial não-vozeada $[\phi]$, mesmo quando /p/ está em ambiente intervocálico (cf. 49), desta forma, concordamos com Campetela (1997) e Pachêco (2001). Todavia chamamos a atenção para o fato de que Campetela (1997) e Pachêco (2001) não tenham desencadeado qualquer discussão acerca da aparente mudança da aspirada $\left[\mathrm{p}^{\mathrm{h}}\right]$ para a fricativa $[\phi]$ neste ambiente. Uma hipótese possível seria de que o registro da oclusiva aspirada $\left[\mathrm{p}^{\mathrm{h}}\right]$ corresponda 
a um momento anterior da língua e teria mudado para realização fricativa $[\phi]$. Essa mudança poderia estar em andamento na língua, sendo motivada pela convivência com outros povos e línguas após o contato. Pontuamos que entre a primeira análise, na década de 70, e a de Pachêco 2001, se passaram, aproximadamente, 30 anos.

Relação entre os fonemas /k/ e /g/

A oclusiva /g/ foi proposta como fonema em todas nas três análises fonológicas discutidas. O fone $[\mathrm{g}]$, além de configurar no conjunto alofônico de /g/, também é interpretado como um dos alofones de /k/. Apesar concordarem sobre o fato de que [g] é um dos alofones de /k/, os autores discordam sobre as condições em que essa alofonia ocorre, portanto, há discrepância sobre os contextos em que as oclusivas velares contrastam e os contextos em que ambos pertencem a uma mesma entidade.

Emmerich (1972, p. 30) afirma que / k/ e /g/ se opõem pela tensão e contrastam em posição intervocálica, no entanto, a pesquisadora afirma que "em nível de maior abstração eles são alternantes morfofonêmicos", apesar de não dar exemplos dessa alofonia.

\begin{tabular}{|c|c|c|c|}
\hline (50.a) & /okep/ & [o'kep’] & 'grande' (EMMERICH, 1972, p. 28) \\
\hline$(50 . b)$ & /ogep/ & [o'gep’] & 'falecido' (EMMERICH, 1972, p. 28) \\
\hline & /maku/ & [ma'ku] & ‘algodão’ (EMMERICH, 1972, p. 28) \\
\hline (51.b) & /maga/ & [ma'ga] & 'até logo' (EMMERICH, 1972, p. 28) \\
\hline
\end{tabular}

Campetela (1997) afirma que /g/ é o único fonema oclusivo vozeado pertencente ao conjunto de fonemas do Ikpeng e confirma a distinção entre / $/$ e /g/ através de exemplos abaixo.

$\begin{array}{ll}\text { (52.a) /megu/ } & \text { /52.b) /maku/ } \\ \text { (53.a) /wago/ } \\ \text { (53.b) /ako/ } \\ \\ \text { (54.a) /tugu/ } \\ \text { (54.b) /yukut/ }\end{array}$

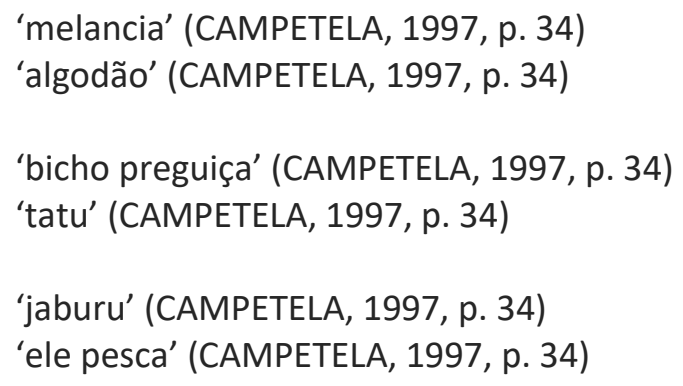

Pachêco (2001) apresenta a oclusiva velar sonora /g/ em seu quadro de fonemas, mas não realiza nenhuma discussão para explicar a classificação deste segmento como tal. O autor apenas menciona que este fone também funciona como alofone de $/ \mathrm{k} /$ em ambiente intervocálico e que este é um processo morfofonológico, o qual nomeia como vozeamento das oclusivas, como podemos observar no único exemplo apresentado.

(55) /i-momt $\int \mathrm{ike} /$ [imomt $\int \mathrm{i}$ 'ge] 'eu estou com dor de cabeça' (PACHÊCO, 2001, p. 47) 
Mesmo que a existência de um fonema /g/ seja consenso entre os três pesquisadores, temos três propostas diferentes para sua distribuição e sua relação com /k/. Enquanto Emmerich (1972) selecione o contexto intervocálico como aquele em se observa a oposição entre /k/ e /g/, Pachêco (2001) prevê que [g] funciona, neste mesmo ambiente, como alofone de /k/. Temos ainda a proposta de Campetela (1997) que apenas afirma a distinção entre esses segmentos sem discutir a distribuição dos alofones. Para analisar as relações de oposição e alofonia que os fonemas velares estabelecem utilizaremos os seguintes exemplos:

\begin{tabular}{|c|c|c|c|}
\hline (56.a) & $\begin{array}{l}\text { /okuro/ } \\
\text { [o.ku'ro] }\end{array}$ & (56.b) & $\begin{array}{l}\text { /oguro/ } \\
\text { [o.gu'ro] }\end{array}$ \\
\hline & okuro & & oguro \\
\hline & 'som do perdigão' & & $\begin{array}{l}\text { 'sucuri' } \\
\text { (ANAT MÏ̈AN) }\end{array}$ \\
\hline
\end{tabular}

(57)
Alalu iget
[a.la'lu] [i'get']
alalu ï-ke-txi
**** 1P-dizer, fazer-N.PAS.
'o que eu vou fazer?' (PURON MÏRAN - HISTÓRIA DO SAPO)

(58)
Anepkoga
yemukut
[ã.nep'.ko'ga]
[yẽ.mu'kut']
anep-ko-ka y-imuku-txi

trazer-IMPER.-PERM. 1A-cheirar-N.PAS.

'Me traga que eu cheiro' (MARURÏ MÏRANGMO - HISTÓRIA DE HOMENS BRANCOS E ÍNDIOS)

$\begin{array}{ll}\text { (59.a) } & \text { lakte } \\ & {[\text { lak`'t }]} \\ & \text { lak-te } \\ & \text { saliva-VBLZ } \\ & \text { 'salivar' } \\ & \text { (CHAGAS, 2013, p. 332) }\end{array}$

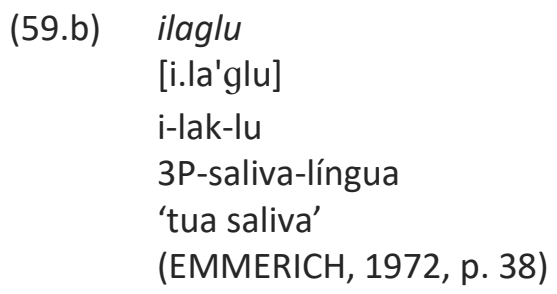

Nos exemplos (56a) e (56b) percebemos claramente o contraste entre / k/ e /g/ quando as oclusivas velares ocorrem dentro de palavra. Já nas ocorrências em (57) e (58) notamos que [g] se comporta como alofone de / $/ \mathrm{k}$ quando o fonema velar desvozeado está em fronteira de morfema diante de líquidas ou entre vogais. Dessa forma, identificamos que quando /k/ e /g/ estão dentro de um lexema se estabelecem relações opositivas, ou seja, são fonema distintos. Porém, em processos em fronteira de morfema que envolvam o fonema / $/$ / entre vogais ou diante de líquidas, a oclusiva velar vozeada [g] se realiza como alofone de sua contraparte desvozeada.

Segmentos [i] e [u]

Para a discussão desses segmentos é necessário tratar também das propostas silábicas presentes em cada investigação, pois a interpretação dos autores acerca do status desses segmentos afeta diretamente as configurações definidas como padrão silábico. Começaremos com 
a proposta de Emmerich (1972) que considera que os segmentos /i/ e /u/ possuem como alofones as vogais assilábicas [i] e [u] quando ocorrem contíguos a vogais que ocupem o núcleo silábico:

\begin{tabular}{|c|c|}
\hline (60) & /uot/ \\
\hline (61) & /mui/ \\
\hline
\end{tabular}

Emmerich (1972) explica que em Ikpeng a sílaba fonética não coincide com a sílaba fonêmica, de forma que todas as configurações silábicas encontradas na língua são compreendidas como sílabas fonéticas, enquanto as configurações mais frequentes - V, VC, CV, CVC - são adotadas como pertencentes ao padrão silábico, nesse caso, são sílabas fonológicas (EMMERICH, 1972, p. 21-22).

Dentre as várias configurações atestadas, Emmerich (1972) encontrou ocorrências do tipo VV, VV, VVV, isto é, sílabas que contém uma vogal no núcleo mais uma ou duas vogais assilábicas antes e/ou após vogal nuclear. A autora notou, ainda, que sílabas do tipo $\mathrm{V}$ variam constantemente com sílabas $V$ na pronúncia dos falantes, como pode ser visto nos exemplos abaixo:

\begin{tabular}{|c|c|c|}
\hline (62) & ['unot'] [u.'ot’] & 'peixe' (EMMERICH, 1972, p.23) \\
\hline & VVC V.VC & \\
\hline (63) & ['muij] [mu.'i] & 'canoa' (EMMERICH, 1972, p.23) \\
\hline (64) & $\begin{array}{l}\text { CVV } \quad \text { CV.V } \\
\text { [geu..'rí) [ge.u'ri] }\end{array}$ & 'minha casa' (EMMERICH, 1972, p.23) \\
\hline & CVV.CV CV.V.CV & \\
\hline
\end{tabular}

Tendo em vista a variação recorrente entre $\mathrm{V}$ e $\mathrm{V}$, apenas configurações do último tipo foram interpretadas como pertencentes ao padrão silábico Ikpeng, enquanto as sílabas $\bigvee$ seriam apenas variantes fonéticas. Dessa forma, de acordo com Emmerich (1972), interpretar as assilábicas [i] e [un] como alofones dos fonemas /i/ e / $\mathrm{u}$ / é uma análise que "representa economia no inventário fonêmico das consoantes sem aumentar o número de vogais, além de ser compatível com o fato de que se dá variação livre entre $\bigvee$ e V"' (EMMERICH, 1972, p.22).

Como apontado anteriormente, a investigação de Campetela (1997) diverge daquela de Emmerich (1972), já que reinterpreta as vogais assilábicas como glides /y/ e /w/. Apesar de terem sido incorporados no inventário consonantal da língua, estes segmentos não se apresentam como consoantes na sílaba Ikpeng, pois segundo a autora passam a constituir sílabas /CVS/, /SVC/, /CSV/ e /VSC/ por sua natureza semivocálica ou semiconsonântica (CAMPETELA, 1997, p. 33). Assim, o padrão silábico Ikpeng integra mais quatro configurações nesta proposta em relação à análise de Emmerich (1972), como podemos ver a seguir:

$\begin{array}{llll}\text { (65) } & \text { /yon'ko/ } & \text { SVC.CV } & \text { 'onça preta' (CAMPETELA, 1997, p. 33) } \\ (66) & \text { /yapi'ga/ } & \text { SV.CV.CV } & \text { 'macaco preto' (CAMPETELA, 1997, p. 33) } \\ (67) & \text { /'muy/ } & \text { CVS } & \text { 'canoa' (CAMPETELA, 1997, p. 33) } \\ \text { (68) } & \text { /o'goy/ } & \text { V.CVS } & \text { 'cobra' (CAMPETELA, 1997, p. 33) }\end{array}$

Pachêco (2001) faz a distinção entre dois tipos de glides: (i) os glides derivados que correspondem às vogais assilábicas [i] e [un]; e (ii) os glides de comportamento consonantal, 
representados por $/ \mathrm{y} /$ e $/ \mathrm{w} / \mathrm{e}$, assim, fonemas na língua. Os primeiros funcionam como alofones dos fonemas /i/ e /u/ quando seguem ou precedem vogal que ocupe o núcleo da sílaba, como podemos observar abaixo:

$\begin{array}{llll}\text { (69) } & \text { /yai/ } & \text { ['jaij] } & \text { 'árvore' (PACHÊCO, 2001, p. 35) } \\ (70) & \text { /pou/ } & \text { ['poun] } & \text { 'porco' (PACHÊCO, 2001, p. 35) } \\ (71) & / \text { uot/ } & \text { ['ưot] } & \text { 'peixe' (PACHÊCO, 2001, p. 35) } \\ (72) & / \text { tuyai/ } & \text { [tu'jai] } & \text { 'rato' (PACHÊCO, 2001, p. 35) } \\ (73) & / \text { muot/ } & \text { ['munot] } & \text { 'você o matou' (PACHÊCO, 2001, p. 35) }\end{array}$

Já os glides /y/ e /w/ podem ocorrer apenas em posição de ataque e geralmente se realizam como fricativas sonoras, [i] e [ $\beta$ ] respectivamente:

\begin{tabular}{|c|c|c|}
\hline /awiana/ & [aßia'na] & 'porco queixada' (PACHÊCO, 2001, p. 36) \\
\hline /tawule/ & [taßu'le] & 'leve’ (PACHÊCO, 2001, p. 36) \\
\hline /t $\int i w a n /$ & {$\left[\mathrm{t} \int \mathrm{i}^{\prime} \beta \mathrm{an}\right]$} & ‘arraia' (PACHÊCO, 2001, p. 36) \\
\hline /yai/ & ['jai] & 'árvore' (PACHÊCO, 2001, p. 36) \\
\hline /tuyai/ & [tu'jai] & 'rato' (PACHÊCO, 2001, p. 36) \\
\hline
\end{tabular}

Pachêco (2001) não explica como os glides derivados se comportam na sílaba Ikpeng. Neste caso, o pesquisador apenas menciona ter notado a variação entre as configurações $\bigvee$ e $V$, além de concordar com a proposta de Emmerich (1972) que compreende as configurações V, VC, CV, CVC como pertencentes ao padrão silábico. Dessa forma, podemos interpretar os glides derivados não pertencem ao padrão silábico fonológico, mas integram configurações fonéticas, apesar de Pachêco (2001) não estabelecer qualquer divisão entre sílaba fonética e sílaba fonológica, como Emmerich (1972).

Para discutir o status fonológico destes segmentos consideramos que seria ideal separar suas ocorrências em dois ambientes: a) precedendo núcleo silábico (/_ V); b) após núcleo silábico (/ V_). Assim, poderíamos verificar como os segmentos [i] e [un] comportam-se em cada um dos ambientes e comparar nossos resultados com as propostas discutidas acima para tais segmentos. No entanto, a carência de dados não nos permite realizar uma discussão satisfatória acerca dos segmentos [i] e [u] no presente momento. Apresentaremos os dados que possuímos para essa análise e realizaremos uma breve discussão para reforçar nossa justificativa:

Precedendo núcleo silábico - / V

(79) [t [ti'wãn] [t tji'ßãn] 'arraia' (PACHÊCO, 2001, p. 36)

Após núcleo silábico - / V

\begin{tabular}{|c|c|}
\hline (80) & [o'goin] \\
\hline (81) & ['t $\int$ oũm] \\
\hline
\end{tabular}

No item (79), extraído de Pachêco (2001), temos aparentemente um comportamento mais consonantal que varia com o fone fricativo bilabial sonoro [ $\beta$ ]. Já afirmamos anteriormente que não possuímos dados que reforcem ou refutem a variação entre o glide [w] e a fricativa [ $\beta$ ] apontada 
pelo autor, o que inviabiliza nossa interpretação acerca do comportamento dos segmentos [i] e [u్n] no ambiente diante de vogal (/_V).

No outro contexto de análise temos o exemplo (81), também de Pachêco (2001), que aponta um comportamento mais vocálico ao assinalar a assilábica [u] após núcleo silábico, porque a vogal assilábica assimila o traço de nasalidade espraiado pelo fonema nasal / $\mathrm{m} /$, se realizando como uma semivogal nasal, processo comum a vogais seguidas por consoantes nasais. No entanto, não temos outros dados que apontem assimilação de nasalidade por parte de semivogais após núcleo silábico, logo, seria necessário realizar testes para verificar a regularidade deste processo e então tratar sobre a ocorrência de vogais assilábicas na língua Ikpeng.

Por fim, apontamos a necessidade de uma nova coleta de dados para a discussão dos segmentos [i] e [un] antes e após núcleo silábico com foco em: a) a variação entre os glides [y] e [w] e as fricativas [i] e [ $\beta$ ] apontadas por Pachêco (2001); e b) a assimilação de nasalidade dos segmentos assilábicos após núcleo silábico.

\section{Considerações Finais}

Nesse estudo, fizemos uma descrição das principais divergências sobre os estudos fonológicos da língua Ikpeng, trazendo dados da pesquisa mais recente de Chagas (narrativas coletadas entre 2009 e 2015). No quadro 2, seguinte, apontamos para um quadro consonantal baseado nas discussões da seção anterior, procurando apontar as possíveis oposições do sistema. Se caráter é provisório, pois depende de um corpus mais robusto e voltado para discussão dos processos morfofonológicos da língua.

Quadro 2: Quadro provisório de fonemas consonantais

\begin{tabular}{|c|c|c|c|c|c|}
\hline \multicolumn{2}{|c|}{ Obstruintes } & $/ \mathrm{p} /$ & $/ \mathrm{t} /$ & $/ \mathrm{t} /$ & $/ \mathrm{k} / \mathrm{g} /$ \\
\hline \multirow{3}{*}{ Soantes } & Nasais & $/ \mathrm{m} /$ & & $/ \mathrm{n} /$ & $/ \mathrm{y} /$ \\
\cline { 2 - 6 } & orais & $/ \mathrm{w} /$ & & $/ \mathrm{r} / / \mathrm{l} /$ & $/ \mathrm{y} /$ \\
\hline
\end{tabular}

Neste breve apanhado, interpretamos a africada / $\mathrm{t} \int /$ como fonema, dividindo com /t/, casos de neutralização diante de vogais altas não-arredondadas /i/ e /ì/. A oclusiva bilabial sonora [b] surge como resultado de um processo de vozeamento do fonema /p/diante de líquidas / $/$ e / $/$, processo que atinge também ao fonema $/ \mathrm{k} /$, realizando-se como $[\mathrm{g}]$. Sobre a fricativa desvozeada $[\phi]$, atesamos sua ocorrência somente diante da vogal alta / $/$ /, ambiente em que o fonema $/ \mathrm{p} /$ não apresenta ocorrências, por isso a consideramos como uma realização de /p/, embora não saibamos qual ou quais traços estão envolvidos nessa mudança. Finalmente, destacamos que não obtivemos resultados satisfatórios na análise dos segmentos [i], [u] e [ $[\beta]$ por falta de dados, mas enfatizamos a necessidade de uma nova coleta de dados visando especialmente: a) a variação entre os glides [y] e [w] e as fricativas [j] e [ $\beta$ ] apontadas por Pachêco (2001); e b) a assimilação de nasalidade dos segmentos assilábicos após núcleo silábico. 


\section{Referências}

CAMPETELA, C. Análise do sistema de marcação de caso nas orações independentes da língua lkpeng (Karib). 1997. Dissertação (Mestrado em Linguística), Instituto de Estudos da Linguagens, Universidade Estadual de Campinas, Campinas, 1997.

CAMPETELA, C. Aspectos prosódicos da língua Ikpeng. 2002. Tese (Doutorado em Linguística), Instituto de Estudos da Linguagens, Universidade Estadual de Campinas, Campinas, 2002.

CHAGAS, A. F. O verbo Ikpeng: um estudo morfossintático e semântico-lexical. 2013. Tese (Doutorado em Linguística), Instituto de Estudos da Linguagens, Universidade Estadual de Campinas, Campinas, 2013.

EMMERICH, C. A fonologia segmental da língua Txicão. 1972. Dissertação (Mestrado em Linguística), Universidade Federal do Rio de Janeiro, Rio de Janeiro, 1972.

HERNANDORENA, C. L. M. Introdução à teoria fonológica. In: BISOL, L. (Org.). Introdução a estudos de fonologia do português brasileiro. 2. ed. Porto Alegre: EDIPUCRS, 1999. p. 11-89.

MEIRA, S.; FRANCHETO, B. The southern Carib languages and the Cariban Family. International Journal of American Linguistic, Chigaco, v. 7, n. 2, p. 127-190, 2005.

PACHÊCO, F. B. Morfossintaxe do verbo Ikpeng (Karib).2001. Tese (Doutorado em Linguística), Instituto de Estudos da Linguagens, Universidade Estadual de Campinas, Campinas, 2001. 